\title{
Antecedent water condition determines carbon exchange response to extreme precipitation events across global drylands
}

Huichen Zhao ( $\nabla$ zhaohc@tea.ac.cn )

Institute of Atmospheric Physics Chinese Academy of Sciences

\section{Xiyan Xu}

Institute of Atmospheric Physics Chinese Academy of Sciences

Gensuo Jia

Institute of Atmospheric Physics Chinese Academy of Sciences

Anzhi Zhang

Institute of Atmospheric Physics Chinese Academy of Sciences

Hesong Wang

School of Ecology and Nature Conservation, Beijing Forestry University

\section{Research Article}

Keywords: dryland, aridity gradient, carbon exchange, extreme precipitation, antecedent water condition, soil moisture

Posted Date: March 9th, 2021

DOl: https://doi.org/10.21203/rs.3.rs-168306/v1

License: (1) This work is licensed under a Creative Commons Attribution 4.0 International License. Read Full License 


\section{Abstract}

The global hydrological cycle is predicted to be intensified under the warming climate, with more extreme precipitation events and longer dry spell in between. Here, we evaluated how extreme precipitation events (EPEs) with antecedent dry (dry-EPEs) and wet (wet-EPEs) water conditions influence carbon exchange along gradient of arid, semi-arid and sub-humid ecosystems based on eddy covariance datasets. After EPEs, ecosystem respiration (Re) and gross primary productivity (GPP) were stimulated by pulses of soil moisture in arid and semi-arid regions, but suppressed by decreased soil temperature in sub-humid region. Antecedent water condition determined asynchronous response of Re and GPP to EPEs, and therefore fluctuations in net carbon balance. Net carbon uptake capacity was enhanced immediately following wet-EPEs because of more rapid and greater response of GPP than Re. However, after dry-EPEs, net carbon uptake capacity decreased immediately and increased thereafter because the response of GPP to dry-EPEs lagged behind Re. More antecedent precipitation further stimulated accumulative net carbon uptake. Along the aridity gradient, duration and magnitude of net carbon release were greater in wetter regions than that in drier regions after dry-EPEs, while net carbon uptake duration was shorter in wetter regions after wet-EPEs. The accumulative net carbon uptake after EPEs decreased with increasing aridity index, indicating that net carbon uptake capacity in drier regions benefited more from EPEs. We concluded that antecedent water conditions and local climate regimes need to be considered when interpreting the response of carbon exchange to EPEs in dryland ecosystems.

\section{Introduction}

Drylands cover around $40 \%$ of the earth's land surface and account for large mass of global net primary production (Shen et al., 2016). Drylands determine the interannual variations in terrestrial carbon sink because they are highly sensitive to climate variation, especially precipitation (AhlstrÖm et al., 2015; Bunting et al., 2017). Precipitation constrains biological and physical processes in drylands and occurs as episodic events ('pulses') separated by periods of low water availability (Collins et al., 2014). Extreme precipitation pulses can have a global effect on the trend and interannual variability of drylands carbon uptake (Ahlström et al., 2015). Frequency of extreme precipitation events (EPEs) has increased and the dry spell between the precipitation pulses is longer than before (Giorgi et al., 2019). It is important to understand how ecosystem carbon exchange responds to EPEs as global drylands experience major shift of precipitation patterns, in order to better estimates future variability of global carbon sink.

Some studies have examined biome-scale responses of carbon exchange to EPEs using in-situ observations. Both precipitation intensity and frequency are important controls of ecosystem processes in drylands because EPEs after an extended dry spell can lead to rapid mineralization and pulses of photosynthesis and respiration with different magnitudes and response time (Huxman et al., 2004; Nielsen and Ball, 2015). A large, but short-lived increased respiration immediately after a precipitation pulse was widely observed across drylands (Sun et al., 2017). The magnitude of soil respiration pulse following rewetting of dry soil has been shown to be dependent on the frequency of dry-wet cycles before EPEs (Yan et al., 2010; Liu et al., 2017; Liu et al., 2019). The increase of carbon assimilation is slower but 
lasts longer than that of respiration (Chen et al., 2009). However, the effects of EPEs and antecedent water condition on subsequent net ecosystem carbon balance are not clear.

Different researches reported biome specific effects of shifted precipitation regimes on net carbon balance. For example, plant productivity and net carbon uptake of a desert shrubland was reported increased because EPEs increase soil moisture and stimulate plant water uptake significantly (Zhang et al., 2019). A temperate grassland was reported to be carbon neutral after EPEs, which could be attributed to the ecosystem resilience to EPEs and the quick recovery of carbon exchange (Hao et al., 2017). A Mediterranean grassland showed net carbon release after EPEs because soil respiration was the only component significantly stimulated by precipitation pulses (Lopez-Ballsesteros et al., 2015). It seemed that climate regimes determine the sensitivity of carbon exchange to fluctuations in soil water availability induced by EPEs (Vicent-Serrano et al., 2013; Liu et al., 2018). However, the response of carbon exchange to EPEs in diverse drylands have not been evaluated integrally.

Eddy covariance technique can continuously monitor ecosystem carbon exchange with high temporal resolution, which can catch the immediate response of the ecosystem to the precipitation events. The growth of global networks of carbon fluxes observation (e.g., FLUXNET) enables integrated researches on how carbon exchange responds to precipitation variation across global drylands. Based on this, we performed an integrated analysis to detect how and to what extent diurnal carbon fluxes and net carbon balance are fluctuated after EPEs and regulated by different antecedent water conditions across global drylands gradient.

\section{Data And Methods}

\subsection{Screening the sites along the aridity gradient}

The FLUXNET2015 dataset (CC-BY-4.0 Data, 'FULLSET') was downloaded from the FLUXNET portal. Sitelevel aridity index was extracted from the CGIAR-CSI Global-PET Dataset (Trabucco and Zomer, 2018). Eddy covariance flux tower sites located in drylands were filtered according to the classification scheme of United Nations Environment Programme (UNEP): arid sites with the aridity index from 0.03 to 0.2 , semiarid sites with aridity index from 0.2 to 0.5 , and sub-humid sites with aridity index from 0.5 to 0.65 arid sites. As a result, there are 6 arid sites, 28 semi-arid sites and 34 sub-humid sites in FLUXNET2015 datasets selected along the aridity gradient.

In addition to the sites included in the FLUXNET2015, we have measured carbon exchange over a semiarid grassland in East Asia since 2010. The field site is located in Songnen Plain (TY site), Jilin Province, China $\left(44.34^{\circ} \mathrm{N}, 122.92^{\circ} \mathrm{E}\right.$, el. $184 \mathrm{~m}$ ) (Table S1). A 20-m tower was established as observation platform. A detailed description of the instrumentation can be found in Zhao et al. (2019). Briefly, measurements of air $\mathrm{CO}_{2} / \mathrm{H}_{2} \mathrm{O}$ density (IRGA, LI-7500, LI-COR Inc., Lincoln, NE, USA) and three-dimensional wind speed (CSAT3, Campbell Scientific Inc., Logan, UT, USA) are recorded at a frequency of $10 \mathrm{~Hz}$. Meteorological data, including air temperature (HMP45C, Vaisala Inc., Helsinki, Finland), photosynthetically active 
radiation (LI190R, LI-COR Inc., Lincoln, NE, USA), soil water content and temperature (CS616, Campbell Scientific Inc.) are recorded simultaneously with $\mathrm{CO}_{2}$ and $\mathrm{H}_{2} \mathrm{O}$ fluxes at 30 -min intervals.

\subsection{Data processing and quality control}

For FLUXNET 2015 dataset, half-hourly eddy covariance (EC) data were quality controlled, friction velocity filtered and gap-filled following the standardized protocols (Papale et al., 2006). For each daily record net ecosystem exchange (NEE), quality control (QC) flags indicate the proportion of measured and good quality gap-filled half-hour data that aggregate to the daily NEE. In this study, to avoid large errors resulted from gap-filling, daily NEE data with QC flags less than $90 \%$ were discarded. Soil moisture (SWC), soil temperature (Ts) and photosynthetic photon flux density (PPFD) were used in this study. We adopted soil moisture tagged SWC_F_MDS_1 and soil temperature tagged TS_F_MDS_1, meaning SWC and Ts of the shallowest layer.

For eddy covariance measurements at TY site, covariances were computed every half-hour to generate fluxes and quality controlled following the FLUXNET standardized protocols as described in Zhao et al. (2019). The half-hour NEE at TY site is partitioned into ecosystem respiration (Re) and gross primary productivity (GPP) after applying data gap filling techniques, and then calculated to mean daily fluxes. GPP is derived by subtracting NEE from Re, thus negative NEE values denote the pathway loop of carbon from the atmosphere to ecosystem while positive values represent the carbon pathway from ecosystem to atmosphere. Daily NEE data with QC flags less than $90 \%$ was discarded. We adopted Ts and SWC recorded at the shallowest layer of $2 \mathrm{~cm}$.

\subsection{Extreme precipitation events filtration and classification}

In this study, an individual EPE for each site was defined as a series of precipitation less than 3 days, with precipitation intensity greater than the 90th percentile of all the precipitation events during observation. Carbon exchange response to an individual EPE may be confounded by leaf area and photosynthetic capacity at different phenological period (Huxman et al., 2004). For example, carbon exchange is more responsive in the early growing season than that in the late growing season (Guo et al., 2016). Therefore, we chose EPEs occurring during the middle growing season which was defined as the period with daily gross primary production (GPP) greater than half of the difference between annual maximum and minimum daily GPP, to minimize the effects of leaf area and phenology on carbon exchange evolution after EPEs. The annual cycle was calculated from January to December, and from July to June of next year for sites located in the Northern and Southern Hemisphere, respectively.

For most drylands, precipitation occurred intensively during middle growing season. The carbon exchange response to EPEs may be confounded by subsequent precipitation. To get the whole carbon exchange pulse process after each EPE, we selected the events without subsequent precipitation at least for three weeks. During this period, if there were data gaps resulted from the filtration of NEE QC flags mentioned in part 2.1 and 2.2, the events were discarded. Finally, we filtered 24 extreme precipitation events (Table S2) from 21 sites, including 8 events at 6 arid sites, 9 events at 9 semi-arid sites and 7 events at 6 sub-humid sites (Fig. 1, Table S1). 
We further classify the events into two groups according to antecedent water conditions. For the events with SWC observation, one-way Analysis of Variance (ANOVA) was used to compare differences in SWC within three weeks before and after the events. If SWC was high and did not increase significantly further after EPEs, these events are identified with sufficient antecedent precipitation and called 'wet-EPEs' hereafter. For the events without SWC observation, we identify antecedent precipitation with larger magnitude than that of the events was sufficient. Otherwise we thought the events without sufficient antecedent precipitation, and the events are called 'dry-EPEs' hereafter (Table S2).

\subsection{Statistical analysis}

In order to minimize the role of random variability in observations, we applied Savitzky-Golay filter to daily NEE, Re and GPP, and environmental factors, including soil water content (SWC), soil temperature (Ts) and photosynthetic photon flux density (PPFD). We calculated 7-day mean NEE, Re, GPP and environmental factors prior to the events as base values. Positive pulsed NEE ( $\triangle \mathrm{NEE}$ ) indicates decreased net carbon sequestration capacity in response to the events, and vice versa. To quantify influence of EPEs on carbon exchange, we defined the number of days required for Re and GPP to recover to its preprecipitation event level of the base value as response duration. The response duration of NEE is determined by Re and GPP because NEE dynamics is the result of the balance of Re and GPP. The timeintegrated amount of NEE, Re and GPP during the response duration was calculated as accumulative pulsed NEE, Re and GPP after the events. Stepwise multiple regression was used to analyze the relationships of diurnal NEE, Re and GPP with concurrent changes in environmental variables.

\section{Result}

\subsection{Climate factors following extreme precipitation events}

Soil moisture increased immediately and peaked on the third day after EPEs in arid and semi-arid regions (Fig. 2a-d). However, SWC was more stimulated by dry-EPEs than wet-EPEs. The peak SWC after dry-EPEs was about 4 and 3 times of the peak SWC after wet-EPEs in arid and semi-arid region, respectively. Antecedent precipitation determined the response of soil moisture to extreme precipitation evens in subhumid region (Fig. 2e-f). Soil moisture increased after dry-EPEs until about 20 days after the events, but maintained a slight decrease even 30 days after wet-EPEs. In arid and semi-arid regions, SWC pulse lasted for about 6 days, much shorter than that in sub-humid region. Soil temperature and PPFD decreased after EPEs. Ts decreased more in arid region than that in semi-arid and sub-humid regions.

\subsection{Carbon flux changes in response to extreme precipitation events}

Re increased in response to EPEs in arid and semi-arid regions with different response time, duration and magnitude, but decreased in sub-humid regions. On the day of dry-EPEs, Re increased about $116.0 \%$ in arid region. Re peaked on the second day after dry-EPEs, and recovered to pre-level about 6 days after dryEPEs (Fig. 2a). Re in semi-arid region responded to EPEs slower than that in arid region, without 
significant difference with the pre-precipitation level on the day of EPEs (Fig. 2c). Re peaked about 4 days after dry-EPEs, and recovered to pre-level about 8 days after dry-EPEs. The peak value of $\triangle R e$ in semi-arid region was significantly higher than that in arid region. Re in sub-humid region was suppressed by about $77.3 \%$ on the day of the dry-EPEs, and was lower than pre-precipitation level until 12 days after the EPEs (Fig. 2e).

Wet-EPEs increased Re in arid region on the day of the events, and the pulse lasted only for about 2 days (Fig. 2b). In semi-arid region, Re peaked about 6 days after wet-EPEs, and recovered to pre-level about 10 days after wet-EPEs, which lasted longer than that in arid region. The magnitude of $\triangle R e$ in semi-arid region was about 2 times of that in arid region. After wet-EPEs, Re in sub-humid region was more suppressed than that after dry-EPEs. Though the duration was similar, the negative peak value of Re was about 2.4 times higher than that after dry-EPEs (Fig. 2f).

The response time, peak value and duration of GPP after EPEs were totally different with Re. In arid region, GPP was not significantly different with pre-level on the day of dry-EPEs, but then increased and peaked on the fourth day, and recovered to pre-precipitation level about 9 days after dry-EPEs (Fig. 2a). In semi-arid region, GPP was suppressed within 2 days after dry-EPEs (Fig. 2c). GPP increased thereafter and became higher than pre-level, peaked about 6 days after dry-EPEs and recovered to pre-precipitation about 10 days after the events. The peak value of GPP in semi-arid region was about 1.5 times of that in arid region. GPP in sub-humid region decreased after dry-EPEs, and the negative peak value was higher than Re (Fig. 2e).

Wet-EPEs induced longer and higher magnitude of GPP response than that of Re. In arid region, GPP peaked on the day of the events with a peak value about 1.8 times of Re (Fig. 2b). The pulse duration was about 9 days, which was much longer than Re. In semi-arid region, GPP responded to wet-EPEs slower than that in arid region (Fig. 2d). GPP increased gradually after wet-EPEs and peaked about 5 days after wet-EPEs. But the peak value of $\triangle$ GPP was about 2 times of that in arid region. In sub-humid region, GPP was suppressed and the peak value was about half of Re (Fig. 2f).

Under the asynchronous responses of Re and GPP, NEE increased after dry-EPEs, and then decreased in all regions (Fig. 2a, 2c and 2e). $\triangle$ NEE peaked up to $0.25 \pm 0.15 \mathrm{gCm}^{-2} \mathrm{~d}^{-1}, 0.56 \pm 0.28 \mathrm{gCm}^{-2} \mathrm{~d}^{-1}$ and $0.42 \pm 0.63 \mathrm{gCm}^{-2} \mathrm{~d}^{-1}$ in arid, semi-arid and sub-humid regions (Table 2). The magnitude of positive pulsed NEE was significantly higher in semi-arid and sub-humid region than that in arid region. The duration of positive pulsed NEE increased with local humidity, and was significantly longer in sub-humid region, about $7.67 \pm 2.52$ days. The magnitude and duration of negative pulsed NEE was not significantly different among all regions. After wet-EPEs, the fluctuation pattern of NEE was totally different from that after dry-EPEs. NEE decreased immediately after wet-EPEs in all regions (Fig. 2b, 2d and 2f). The magnitude of the negative $\triangle$ NEE peak was not significantly different among different regions, but the duration decreased from arid region to sub-humid region, and was significantly shorter in sub-humid region (Table 2). 
Table 1

Mean extreme precipitation events intensity, antecedent precipitation intensity within 3 weeks before the events and mean magnitude and duration of SWC, Ts and PPFD pulses. (Mean \pm SD)

\begin{tabular}{|c|c|c|c|c|c|c|}
\hline & \multicolumn{3}{|c|}{ Dry-EPEs } & \multicolumn{3}{|c|}{ Wet-EPEs } \\
\hline & Arid & $\begin{array}{l}\text { Semi- } \\
\text { arid }\end{array}$ & $\begin{array}{l}\text { Sub- } \\
\text { humid }\end{array}$ & Arid & $\begin{array}{l}\text { Semi- } \\
\text { arid }\end{array}$ & $\begin{array}{l}\text { Sub- } \\
\text { humid }\end{array}$ \\
\hline $\begin{array}{l}\text { Extreme precipitation } \\
(\mathrm{mm})\end{array}$ & $\begin{array}{l}45.4 \pm \\
27.1 \mathrm{a}\end{array}$ & $\begin{array}{l}42.4 \pm \\
15.0 \mathrm{a}\end{array}$ & $\begin{array}{l}19.2 \pm \\
9.4 \mathrm{~b}\end{array}$ & $\begin{array}{l}24.9 \pm \\
6.0 \mathrm{a}\end{array}$ & $\begin{array}{l}39.3 \pm \\
20.2 \mathrm{~b}\end{array}$ & $\begin{array}{l}18.8 \pm \\
9.9 a\end{array}$ \\
\hline $\begin{array}{l}\text { Antecedent precipitation } \\
(\mathrm{mm})\end{array}$ & $\begin{array}{l}15.3 \pm \\
14.4 \mathrm{a}\end{array}$ & $\begin{array}{l}27.6 \pm \\
21.6 \mathrm{~b}\end{array}$ & $\begin{array}{l}7.6 \pm \\
6.6 \mathrm{c}\end{array}$ & $\begin{array}{l}87.3 \pm \\
6.7 a\end{array}$ & $\begin{array}{l}42.8 \pm \\
13.7 \mathrm{~b}\end{array}$ & $\begin{array}{l}75.0 \pm \\
32.7 \mathrm{a}\end{array}$ \\
\hline Magnitude of $\triangle S W C(\%)$ & $\begin{array}{l}4.0 \pm \\
1.4 \mathrm{a}\end{array}$ & $\begin{array}{l}4.6 \pm \\
3.4 a\end{array}$ & $\begin{array}{l}1.8 \pm \\
1.2 \mathrm{~b}\end{array}$ & 0.9 & $\begin{array}{l}2.0 \pm \\
1.7 \mathrm{a}\end{array}$ & $\begin{array}{l}-1.3 \pm \\
1.1 \mathrm{~b}\end{array}$ \\
\hline $\begin{array}{l}\text { Duration of SWC pulse } \\
\text { (d) }\end{array}$ & $\begin{array}{l}6.8 \pm \\
0.8 \mathrm{a}\end{array}$ & $\begin{array}{l}6.4 \pm \\
0.6 \mathrm{a}\end{array}$ & $\begin{array}{l}13.0 \pm \\
8.9 \mathrm{~b}\end{array}$ & 5.0 & $\begin{array}{l}6.5 \pm \\
2.5 \mathrm{a}\end{array}$ & $>30.0 \mathrm{~b}$ \\
\hline Magnitude of $\Delta \mathrm{Ts}\left({ }^{\circ} \mathrm{C}\right)$ & $\begin{array}{l}-3.1 \pm \\
1.7 a\end{array}$ & $\begin{array}{l}-0.7 \pm \\
0.4 \mathrm{~b}\end{array}$ & $\begin{array}{l}-1.6 \pm \\
1.5 c\end{array}$ & $\begin{array}{l}-1.8 \pm \\
1.6 a\end{array}$ & $\begin{array}{l}-0.7 \pm \\
0.9 b\end{array}$ & $\begin{array}{l}-1.1 \pm \\
1.2 \mathrm{c}\end{array}$ \\
\hline Duration of Ts pulse (d) & $\begin{array}{l}8.3 \pm \\
3.0 \mathrm{a}\end{array}$ & $\begin{array}{l}5.7 \pm \\
2.5 \mathrm{~b}\end{array}$ & $\begin{array}{l}8.0 \pm \\
7.9 \mathrm{a}\end{array}$ & $\begin{array}{l}6.7 \pm \\
1.5 \mathrm{a}\end{array}$ & $\begin{array}{l}7.0 \pm \\
2.7 \mathrm{a}\end{array}$ & $\begin{array}{l}7.8 \pm \\
3.8 \mathrm{a}\end{array}$ \\
\hline $\begin{array}{l}\text { Magnitude of } \triangle \text { PPFD } \\
\left(\mu \mathrm{molm}^{-2} \mathrm{~s}^{-1}\right)\end{array}$ & $\begin{array}{l}-104.9 \pm \\
66.3 a\end{array}$ & $\begin{array}{l}-66.8 \pm \\
67.0 \mathrm{~b}\end{array}$ & $\begin{array}{l}-51.3 \pm \\
44.5 b\end{array}$ & $\begin{array}{l}-24.4 \pm \\
23.4 a\end{array}$ & $\begin{array}{l}-123.5 \pm \\
170.7 b\end{array}$ & $\begin{array}{l}-96.6 \pm \\
41.9 \mathrm{~b}\end{array}$ \\
\hline $\begin{array}{l}\text { Duration of PPFD pulse } \\
\text { (d) }\end{array}$ & $\begin{array}{l}5.0 \pm \\
2.4 a\end{array}$ & $\begin{array}{l}4.0 \pm \\
1.8 \mathrm{a}\end{array}$ & $\begin{array}{l}9.0 \pm \\
4.0 \mathrm{~b}\end{array}$ & $\begin{array}{l}3.0 \pm \\
2.0 \mathrm{a}\end{array}$ & $\begin{array}{l}3.3 \pm \\
2.5 a\end{array}$ & $\begin{array}{l}16.0 \pm \\
5.4 \mathrm{~b}\end{array}$ \\
\hline
\end{tabular}


Table 2

Mean magnitude of positive and negative NEE pulses, duration of positive and negative NEE pulses, total duration and cumulative pulsed NEE. (Mean \pm SD)

\begin{tabular}{|c|c|c|c|c|c|c|}
\hline & \multicolumn{3}{|c|}{ Dry-EPEs } & \multicolumn{3}{|c|}{ Wet-EPEs } \\
\hline & Arid & $\begin{array}{l}\text { Semi- } \\
\text { arid }\end{array}$ & $\begin{array}{l}\text { Sub- } \\
\text { humid }\end{array}$ & Arid & $\begin{array}{l}\text { Semi- } \\
\text { arid }\end{array}$ & $\begin{array}{l}\text { Sub- } \\
\text { humid }\end{array}$ \\
\hline $\begin{array}{l}\text { Magnitude of positive } \\
\triangle \text { NEE }\left(\mathrm{gCm}^{-2} \mathrm{~d}^{-1}\right)\end{array}$ & $\begin{array}{l}0.25 \pm \\
0.15 a\end{array}$ & $\begin{array}{l}0.56 \pm \\
0.28 \mathrm{~b}\end{array}$ & $\begin{array}{l}0.42 \pm \\
0.63 \mathrm{~b}\end{array}$ & / & / & l \\
\hline $\begin{array}{l}\text { Duration of positive } \triangle \mathrm{NEE} \\
\text { (d) }\end{array}$ & $\begin{array}{l}4.33 \pm \\
2.80 \mathrm{a}\end{array}$ & $\begin{array}{l}5.50 \pm \\
1.87 a\end{array}$ & $\begin{array}{l}7.67 \pm \\
2.52 \mathrm{~b}\end{array}$ & / & / & / \\
\hline $\begin{array}{l}\text { Magnitude of negative } \\
\Delta \operatorname{NEE}\left(\mathrm{gCm}^{-2} \mathrm{~d}^{-1}\right)\end{array}$ & $\begin{array}{l}-0.26 \pm \\
0.30 a\end{array}$ & $\begin{array}{l}-0.31 \pm \\
0.46 a\end{array}$ & $\begin{array}{l}-0.40 \pm \\
0.44 a\end{array}$ & $\begin{array}{l}-0.47 \pm \\
0.02 a\end{array}$ & $\begin{array}{l}-0.45 \pm \\
0.45 a\end{array}$ & $\begin{array}{l}-0.51 \pm \\
0.37 a\end{array}$ \\
\hline $\begin{array}{l}\text { Duration of negative } \triangle \mathrm{NEE} \\
\text { (d) }\end{array}$ & $\begin{array}{l}9.83 \pm \\
4.26 \mathrm{a}\end{array}$ & $\begin{array}{l}7.80 \pm \\
4.92 \mathrm{a}\end{array}$ & $\begin{array}{l}9.50 \pm \\
3.46 \mathrm{a}\end{array}$ & $\begin{array}{l}10.33 \\
\pm 4.16 \mathrm{a}\end{array}$ & $\begin{array}{l}9.00 \pm \\
2.44 a\end{array}$ & $\begin{array}{l}7.00 \pm \\
2.83 \mathrm{~b}\end{array}$ \\
\hline Total duration (d) & $\begin{array}{l}14.17 \pm \\
4.07 \mathrm{a}\end{array}$ & $\begin{array}{l}12.80 \pm \\
3.11 \mathrm{a}\end{array}$ & $\begin{array}{l}17.18 \pm \\
4.04 b\end{array}$ & $\begin{array}{l}10.33 \\
\pm 4.16 \mathrm{a}\end{array}$ & $\begin{array}{l}9.00 \pm \\
2.44 a\end{array}$ & $\begin{array}{l}7.00 \pm \\
2.83 \mathrm{~b}\end{array}$ \\
\hline $\begin{array}{l}\text { Cumulative NEE }\left(\mathrm{gCm}^{-2} \mathrm{~d}^{-}\right. \\
\left.{ }^{1}\right)\end{array}$ & $\begin{array}{l}-1.83 \pm \\
1.09 a\end{array}$ & $\begin{array}{l}-0.41 \pm \\
1.75 b\end{array}$ & $\begin{array}{l}0.16 \pm \\
1.43 c\end{array}$ & $\begin{array}{l}-3.65 \pm \\
2.14 a\end{array}$ & $\begin{array}{l}-2.87 \pm \\
0.26 a\end{array}$ & $\begin{array}{l}-1.86 \pm \\
1.53 b\end{array}$ \\
\hline \multicolumn{7}{|c|}{$\begin{array}{l}\text { Different letters behind the numbers indicate significant differences }(P<0.05) \text { among arid, semi-arid } \\
\text { and sub-humid regions. }\end{array}$} \\
\hline
\end{tabular}

The relationships between diurnal carbon fluxes and environmental factors were analyzed to understand how EPEs induced carbon fluxes dynamics. The relationships between carbon fluxes and all factors are represented by the results of a stepwise multiple linear regression analysis in Table S3, and summarized in Fig. 3. For arid and semi-arid regions, SWC dominated carbon fluxes dynamics after EPEs (Fig. 3a and 3d). Sub-humid regions are not significantly sensitive to the SWC with the only negative relationship between SWC and GPP after dry-EPEs (Fig. 3a). Compared with arid and semi-arid regions, NEE, Re and GPP in sub-humid regions were sensitive to the soil temperature change following the EPEs (Fig. $3 \mathrm{~b}$ and $3 e)$. NEE, Re and GPP declined significantly with decreasing Ts $(p<0.05)$, regardless of antecedent water availability. PPFD change following EPEs only had influences on GPP, and thus determined the sign of NEE fluctuations in semi-arid and sub-humid regions (Fig. $3 \mathrm{c}$ and 3 f). Significant positive relationships between PPFD and GPP induced negative relationships between PPFD and NEE, indicating enhanced carbon uptake capacity with increasing PPFD following EPEs in semi-arid and sub-humid regions.

\subsection{Accumulative carbon fluxes in response to EPEs along aridity gradient}


For an assessment of carbon balance change following EPEs, we analyzed accumulative pulsed Re, GPP and NEE of the pulse events following EPEs along aridity gradient (Fig. 4). The response of accumulative pulsed carbon exchanges to EPEs was influenced by local aridity index. Following the EPEs with similar precipitation intensity and antecedent precipitation, accumulative pulsed Re and GPP decreased with increasing aridity index, positive in regions with aridity index lower than 0.50 , but mostly negative in regions with aridity index higher than 0.50 (Fig. 4a-d). Compared with Re, accumulative pulsed GPP tracked more closely to the variations in aridity index. Under the balance of Re and GPP, accumulative pulsed NEE increased with local aridity index, ranged from negative to positive with the increase in aridity index (Fig. 4e-f). NEE in the regions with aridity index lower than 0.4 was generally negative, indicating increased net carbon uptake capacity, but was mostly positive in the regions with aridity index higher than 0.4. Accumulative pulsed NEE after the events in arid, semi-arid and sub-humid region are $-2.23 \pm$ $1.81 \mathrm{gCm}^{-2},-1.39 \pm 1.21 \mathrm{gCm}^{-2}$ and $-0.35 \pm 1.48 \mathrm{gCm}^{-2}$, respectively.

EPEs of higher precipitation intensity enabled more accumulative pulsed Re and GPP than EPEs of lower precipitation intensity (Fig. $4 \mathrm{a}$ and $4 \mathrm{c}$ ). In regions with aridity index lower than 0.4 , accumulative pulsed GPP generally increased more than Re. Thus EPEs of higher precipitation intensity stimulated more net carbon uptake (negative NEE) in the regions with aridity index lower than 0.4 , or reduced net carbon release (positive NEE) in the regions with aridity index higher than 0.4 (Fig. 4e).

Accumulative Re showed negative relationships with antecedent precipitation (Fig. 4b). More antecedent precipitation decreased accumulative carbon release by Re. Accumulative pulsed GPP showed no significant pattern with varied antecedent precipitation (Fig. 4d). EPEs with more antecedent precipitation tended to enhance more or depress less net carbon uptake capacity (Fig. 4f).

\section{Discussion}

\subsection{Effect of antecedent water condition on carbon exchange pulses}

Antecedent water condition determined response pattern of carbon exchange to the extreme precipitation events. The influence of precipitation intensity on carbon exchange was widely reported (Chen et al., 2009; Willliams et al., 2009; Zeppel et al., 2014; Guo et al., 2016). Accumulation of respiration substrates are highly influenced by antecedent water conditions. Most plant and microbes decreased physiological activity, rather than using the limited water and resources to maintain activity under dry condition, thus more litters and nutrients were accumulated (Austin et al., 2004; Wang et al., 2018). Once dry-EPEs occurred, soil surface re-wetting increases microbial activity (Barnard et al., 2015), and available litter and nutrients provide organic carbon to allow immediate respiration pulse (Kim et al., 2012; Ma et al., 2012). Carbon assimilation was provoked afterwards when water infiltrated deeper for plant roots to absorb.

In arid and semi-arid regions, Re and GPP increased after dry-EPEs but response of GPP to dry-EPEs lagged about $2-3$ days behind Re. This is because plants can utilize deeper soil water even surface soil 
water dries out (Chen et al., 2009), and net carbon uptake capacity increased gradually. In sub-humid region, temperature was important in controlling carbon exchange (Tiemoko et al., 2020). Re and GPP fluctuated following soil temperature well, thus decreased after EPEs. After dry-EPEs, Re decreased more

slightly than GPP because soil organic carbon and nutrients needed for ecosystem respiration were more accumulated before the events (Austin et al., 2004; Inglima et al., 2009), relieving the suppression of decreased Ts to some extent. Thus dry-EPEs cause immediately increase in net carbon uptake capacity across all drylands.

Carbon balance change after wet-EPEs were different from that after dry-EPEs. SWC was high before the events and was not stimulated significantly by wet-EPEs compared with dry-EPEs (Table S2). The accumulation of soil organic matters, litters and nutrients for respiration before wet-EPEs are less than dry-EPEs (Austin et al., 2004; Wang et al., 2018). In arid and semi-arid regions, plant characteristics are accustomed to the persistent wet condition, including the new growth of roots and leaves, resulting in more rapid and greater response of photosynthesis than respiration to wet-EPEs (Chen et al., 2009; Munson et al., 2010). Thus net carbon uptake capacity increased once the events occurred, and decreased with the gradually declining GPP. Similarly, Re in sub-humid region was dramatically suppressed after wet-EPEs because soil organic carbon and nutrients needed for ecosystem respiration were more consumed under antecedent sufficient water condition (Austin et al., 2004; Inglima et al., 2009).

The diverse responses of Re to dry-EPEs and wet-EPEs determined that accumulative pulsed Re after EPEs had negative relationship between antecedent precipitation (Fig. 4b). Accumulative pulsed GPP did not show clear relationship with antecedent precipitation. Thus more carbon were released by respiration subject to drying before EPEs than continuously wet soils. Dry periods between precipitation events are projected to be extended with the increasing frequency of EPEs in the coming decades (Kirchmeier-Young et al., 2020), which indicates that net carbon uptake capacity may be weaken by prolonged antecedent dry spell.

\subsection{The response of carbon exchange to EPEs along drylands gradient}

Based on integrated analysis, this study showed that the accumulative pulsed NEE fluctuated from negative to positive with the increase of aridity index, indicating net carbon uptake capacity of drier region benefited more from EPEs than wetter region. Magnitude and duration of carbon exchange pulses after EPEs determined the accumulative net carbon uptake after the EPEs (Huxman et al., 2004). Re and GPP fluctuated asynchronously after EPEs, resulting in NEE fluctuation as discussed in Sect. 4.1.

Duration of NEE pulses is determined by the duration of Re and GPP fluctuation (Fig. 2). After dry-EPEs, the duration of decreased net carbon uptake capacity increased with local aridity index. Response of GPP was more delayed than $\mathrm{Re}$ in semi-arid region than arid region, resulting in longer duration of decreased net carbon uptake capacity once dry-EPEs occurred (Table 2). It was reported that carbon assimilation in arid biomes are highly sensitive to water fluctuation, but semi-arid biomes show less sensitive responses 
to water fluctuation than arid biomes (Vicente-Serrano et al., 2013; Hoofs et al., 2018), leading to slower response of GPP in semi-arid region than arid region. In sub-humid region, GPP decreased much more than Re and the duration of decreased net carbon uptake capacity was longest among all the regions. Net carbon uptake capacity increased then because of the longer response of GPP than Re to dry-EPEs. But duration of increased net carbon uptake capacity was not significantly different among all the regions.

After wet-EPEs, duration of increased carbon uptake capacity was longest in arid region, but shortest in sub-humid region. It was reported that wetter region had more soil microbial biomass or nutrient than drier region (Campo et al., 2016; Wang et al., 2016; Hawkes et al., 2020). Soil microbial biomass acted as soil respiratory substrate and Re decreased quicker in arid region than semi-arid region because of the quicker depleted substrate in arid region after wet-EPEs. Duration of GPP was similar in arid and semiarid regions, which led to longer duration of negative pulsed NEE in arid region than semi-arid region. Although Re decreased following decreased Ts after wet-EPEs, Re in sub-humid region recovered rapidly after the events, resulting in shortest NEE pulse duration.

The magnitude difference between Re and GPP determined the magnitude of NEE pulse. After dry-EPEs, the maximum difference between Re and GPP in semi-arid region was greater in semi-arid region than arid region, resulting in larger magnitude of pulsed positive NEE in semi-arid region and contributing to larger net carbon capacity decrease in semi-arid region. That might be attributed to more soil respiratory substrate (Campo et al., 2016; Wang et al., 2016; Hawkes et al., 2020) in semi-arid region and greater pulsed Re once dry-EPEs occurred. However, the sensitivity of carbon assimilation to EPEs was lower in semi-arid region than arid region (Vicente-Serrano et al., 2013; Hoofs et al., 2018), leading to slower response of GPP to dry-EPEs and the magnitude difference between Re and GPP was enlarged. There was more soil respiratory substrate in sub-humid region and the much slighter decrease in Re than GPP caused greater magnitude of positive pulsed NEE than semi-arid and arid regions after dry-EPEs. The magnitudes of negative pulsed NEE after dry-EPEs and wet-EPEs along the aridity index were not significant (Table 2).

It is necessary to point out that although we have studied carbon exchange responses to EPEs integrally in global drylands, this analysis still based on limited extreme precipitation events due to limited number of observations in drylands and the strict criteria of events screening. More observations with high spatial and temporal resolution are needed to covering more complex global dryland types. Besides, this study focuses on carbon exchange dynamics after single EPE. The effects of EPEs on carbon exchange may decline with successive drying and rewetting cycles, possibly as a result of a limited pool of labile substrates (Kim et al., 2012). Thus long-term studies are needed to investigate how drylands carbon uptake capacity shifts after repetitive dry-wet cycles.

\section{Conclusion}

The results from this study suggest that extreme precipitation events led fluctuations in Re and GPP by triggering soil moisture pulse in arid and semi-arid region, but by soil temperature in sub-humid region. 
Antecedent water condition determined the response pattern of carbon exchange to EPEs. Dry condition before EPEs induced immediate carbon release pulses, which was largely absent if there was sufficient antecedent precipitation. Accumulative pulsed carbon exchange had negative relationships with antecedent precipitation. Net carbon uptake capacity in drier regions benefits more from the events than wetter region, because of shorter duration of decreased net carbon uptake capacity and lower positive NEE magnitude after dry-EPEs, and longer duration of increased net carbon uptake capacity after wetEPEs. Frequency of EPEs increased with longer dry spell between the events. Further observations and experiments on impacts of extreme precipitation events and antecedent water condition across global drylands are needed to get in-depth insight into how carbon uptake capacity of drylands change under future precipitation regime.

\section{Declarations}

\section{Acknowledgements}

We thank FLUXNET for the data supports for this study.

\section{Funding}

This study is funded by the National Key Research and Development program of China (2016YFA0600303) and Strategic Priority Research Program of Chinese Academy of Sciences, CASEarth (XDA19030401).

\section{Declaration of Competing Interest}

The authors have no competing interest to declare.

\section{Data availability}

Aridity index was extracted from the CGIAR-CSI Global-PET Dataset: http://www.cgiarcsi.org/data/global-aridity-and-pet-database. FLUXNET dataset are extracted at http://fluxnet.fluxdata.org/data/fluxnet2015-dataset. Datasets of Tongyu and Maodeng sites are available from the corresponding author on reasonable request.

\section{Author contribution}

Huichen Zhao provided the idea, performed the analysis and drafted the paper. Xiyan Xu and Gensuo Jia guided the analysis and revised the paper. Anzhi Zhang and Hesong Wang maintained flux observation at Tongyu site and helped to improve the paper.

\section{References}


1. Ahlström A, Raupach MR, Schurgers $G$ et al (2015) The dominant role of semi-arid ecosystems in the trend and variability of the land $\mathrm{CO}_{2}$ sink. Science 348(6237):895-899.

https://doi.org/10.1126/science.aaa1668

2. Austin AT, Yahdjian L, Stark JM et al (2004) Water pulses and biogeochemical cycles in arid and semiarid ecosystems. Oecologia 141(2):221-235. https://doi.org/10.1007/s00442-004-1519-1

3. Barnard RL, Osborne CA, Firestone MK (2015) Changing precipitation pattern alters soil microbial community response to wet-up under a Mediterranean-type climate. The ISME journal 9(4): 946-957. https://doi.org/0.1038/ismej.2014.192

4. Bunting EL, Munson SM, Villarreal ML (2017) Climate legacy and lag effects on dryland plant communities in the southwestern US. Ecol Ind 74:216-229.

https://doi.org/10.1016/j.ecolind.2016.10.024

5. Chen S, Lin G, Huang J et al (2009) Dependence of carbon sequestration on the differential responses of ecosystem photosynthesis and respiration to rain pulses in a semiarid steppe. Glob Change Biol 15(10):2450-2461. https://doi.org/10.1111/j.1365-2486.2009.01879.x

6. Collins SL, Belnap J, Grimm NB et al (2014) A multiscale, hierarchical model of pulse dynamics in arid-land ecosystems. Annu Rev Ecol Evol Syst 45:397-419. https://doi.org/10.1146/annurevecolsys-120213-091650

7. Giorgi F, Raffaele F, Coppola E (2019) The response of precipitation characteristics to global warming from climate projections. Earth Sys Dyn 10(1):73-89. https://doi.org/10.5194/esd-10-73-2019

8. Guo Q, Li S, Hu Z et al (2016) Responses of gross primary productivity to different sizes of precipitation events in a temperate grassland ecosystem in Inner Mongolia, China. Journal of Arid Land 8(1):36-46. https://doi.org/10.1007/s40333-015-0136-7

9. Hao YB, Zhou CT, Liu WJ et al (2017) Aboveground net primary productivity and carbon balance remain stable under extreme precipitation events in a semiarid steppe ecosystem. Agric For Meteorol 240:1-9. https://doi.org/10.1016/j.agrformet.2017.03.006

10. Huxman TE, Snyder KA, Tissue D et al (2004) Precipitation pulses and carbon fluxes in semiarid and arid ecosystems. Oecologia 141(2):254-268. https://doi.org/10.1007/s00442-004-1682-4

11. Inglima I, Alberti G, Bertolini T et al (2009) Precipitation pulses enhance respiration of Mediterranean ecosystems: the balance between organic and inorganic components of increased soil $\mathrm{CO}_{2}$ efflux. Glob Change Biol 15(5):1289-1301. https://doi.org/10.1111/j.1365-2486.2008.01793.x

12. Kim DG, Vargas R, Bond-Lamberty B et al (2012) Effects of soil rewetting and thawing on soil gas fluxes: a review of current literature and suggestions for future research. Biogeosciences 9(7):2459. https://doi.org/10.5194/bgd-8-9847-2011

13. Kirchmeier-Young MC, Zhang X (2020) Human influence has intensified extreme precipitation in North America. Proceedings of the National Academy of Sciences. https://doi.org/10.1073/pnas.1921628117 
14. Liu WJ, Li LF, Biederman JA et al (2017) Repackaging precipitation into fewer, larger storms reduces ecosystem exchanges of $\mathrm{CO}_{2}$ and $\mathrm{H}_{2} \mathrm{O}$ in a semiarid steppe. Agric For Meteorol 247:356-364. https://doi.org/10.1016/j.agrformet.2017.08.029

15. Liu L, Zhang Y, Wu S et al (2018) Water memory effects and their impacts on global vegetation productivity and resilience. Scientific reports 8(1):1-9. https://doi.org/10.1038/s41598-018-21339-4

16. Liu Y, Liu S, Miao R et al (2019) Seasonal variations in the response of soil $\mathrm{CO}_{2}$ efflux to precipitation pulse under mild drought in a temperate oak (Quercus variabilis) forest. Agric For Meteorol 271:240250. https://doi.org/10.1016/j.agrformet.2019.03.009

17. López-Ballesteros A, Serrano-Ortiz P, Sánchez-Cañete EP et al (2016) Enhancement of the net $\mathrm{CO}_{2}$ release of a semiarid grassland in SE Spain by rain pulses. Journal of Geophysical Research: Biogeosciences 121(1):52-66. https://doi.org/10.1002/2015JG003091

18. Ma S, Baldocchi DD, Hatala JA et al (2012) Are rain-induced ecosystem respiration pulses enhanced by legacies of antecedent photodegradation in semi-arid environments? Agric For Meteorol 154:203213. https://doi.org/10.1016/j.agrformet.2011.11.007

19. Munson SM, Benton TJ, Lauenroth WK et al (2010) Soil carbon flux following pulse precipitation events in the shortgrass steppe. Ecol Res 25(1):205-211. https://doi.org/10.1007/s11284-009-06510

20. Nielsen UN, Ball BA (2015) Impacts of altered precipitation regimes on soil communities and biogeochemistry in arid and semi-arid ecosystems. Global change biology 21(4):1407-1421. https://doi.org/10.1111/gcb.12789

21. Papale D, Reichstein M, Canfora E et al (2006) Towards a more harmonized processing of eddy covariance $\mathrm{CO}_{2}$ fluxes: algorithms and uncertainty estimation. Biogeosciences Discussions 3(4):961-992. https://doi.org/10.5194/bgd-3-961-2006

22. Shen W, Jenerette GD, Hui D et al (2016) Precipitation legacy effects on dryland ecosystem carbon fluxes: direction, magnitude and biogeochemical carryovers. Biogeosciences 13(2). https://doi.org/10.5194/bg-13-425-2016

23. Sun Q, Meyer WS, Koerber GR et al (2017) Prior rainfall pattern determines response of net ecosystem carbon exchange to a large rainfall event in a semi-arid woodland. Agr Ecosyst Environ 247:112-119. https://doi.org/10.1016/j.agee.2017.06.032

24. Tiemoko DT, Yoroba F, Diawara A et al (2020) Understanding the Local Carbon Fluxes Variations and Their Relationship to Climate Conditions in a Sub-Humid Savannah-Ecosystem during 2008-2015: Case of Lamto in Cote d'Ivoire. Atmospheric Climate Sciences 10(2):186-205. https://doi.org/10.4236/acs.2020.102010

25. Trabucco A, Zomer RJ (2018) Global Aridity Index and Potential Evapo-Transpiration (ET0) Climate Database v2. CGIAR Consortium for Spatial Information (CGIAR-CSI). Published online, available from the CGIAR-CSI GeoPortal at https://cgiarcsi.community

26. Vicente-Serrano SM, Gouveia C, Camarero JJ et al (2013) Response of vegetation to drought timescales across global land biomes. Proceedings of the National Academy of Sciences 110(1): 52-57. 
https://doi.org/ 10.1073/pnas.1207068110

27. Wang Q, He N, Liu Y et al (2016) Strong pulse effects of precipitation events on soil microbial respiration in temperate forests. Geoderma 275: 67-73. https://doi.org/ 10.1016/j.geoderma.2016.04.016

28. Wang YH, Chen JQ, Zhou GS et al (2018) Predominance of precipitation event controls ecosystem $\mathrm{CO}_{2}$ exchange in an Inner Mongolian desert grassland, China. Journal of Cleaner Production 197 (Part 1): 781-793. https://doi.org/10.1016/j.jclepro.2018.06.107

29. Williams CA, Hanan N, Scholes RJ et al (2009) Complexity in water and carbon dioxide fluxes following rain pulses in an African savanna. Oecologia 161(3): 469-480. https://doi.org/ 10.1007/s00442-009-1405-y

30. Yan L, Chen S, Huang J et al (2010) Differential responses of auto-and heterotrophic soil respiration to water and nitrogen addition in a semiarid temperate steppe. Glob Change Biol 16(8):2345-2357. https://doi.org/10.1111/j.1365-2486.2009.02091.x

31. Zeppel MJ, Wilks JV et al (2014) Impacts of extreme precipitation and seasonal changes in precipitation on plants. Biogeosciences 11:3083-3093. https://doi.org/10.5194/bg-11-3083-2014

32. Zhang C, Li XY, Wang Y et al (2019) Responses of two desert shrubs to simulated rainfall pulses in an arid environment, northwestern China. Plant Soil 435(1-2):239-255.

https://doi.org/10.1007/s11104-018-3892-2

33. Zhao H, Jia G, Wang H et al (2019) Seasonal and interannual variations in carbon fluxes in East Asia semi-arid grasslands [J]. Science of the total environment 668:1128-1138.

https://doi.org/10.1016/j.scitotenv.2019.02.378

\section{Figures}

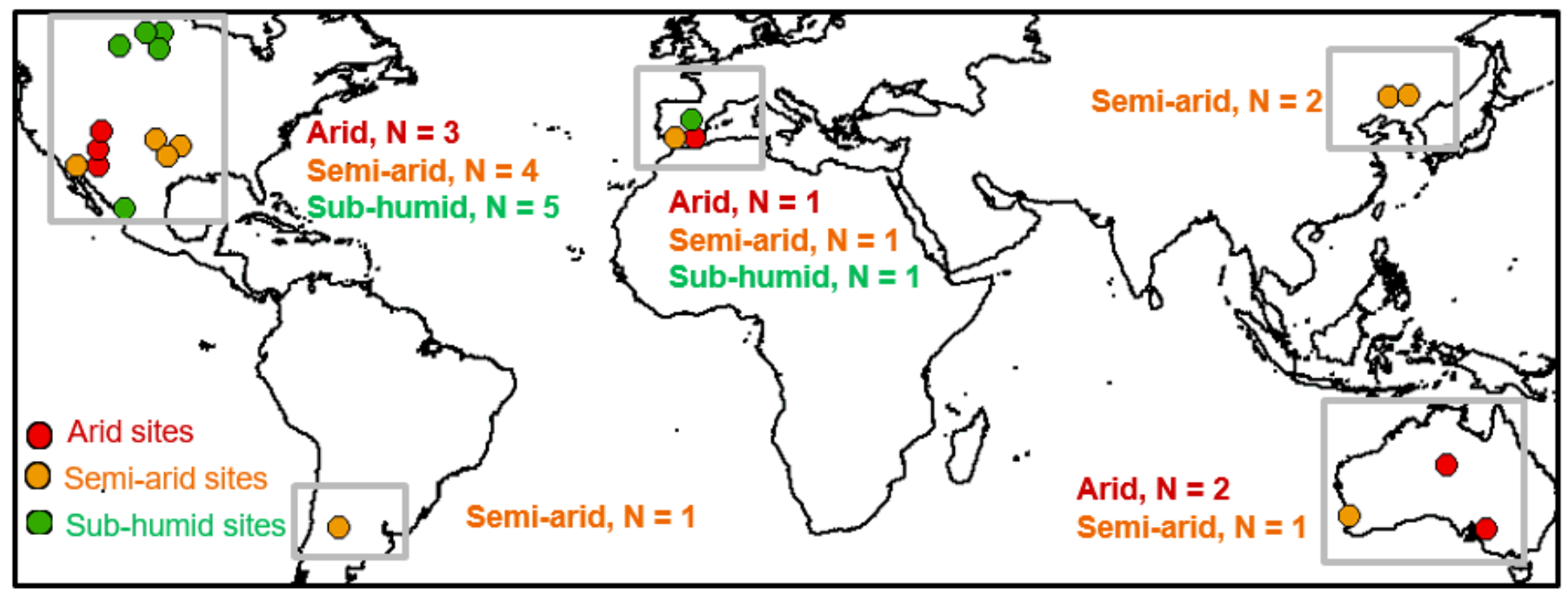

Figure 1 
Study sites location and their aridity classification. Red, orange and green circles denote the sites in the arid, semi-arid and sub-humid climate, respectively, as determined by aridity index. Site locations are slightly altered to avoid overlap. Note: The designations employed and the presentation of the material on this map do not imply the expression of any opinion whatsoever on the part of Research Square concerning the legal status of any country, territory, city or area or of its authorities, or concerning the delimitation of its frontiers or boundaries. This map has been provided by the authors.
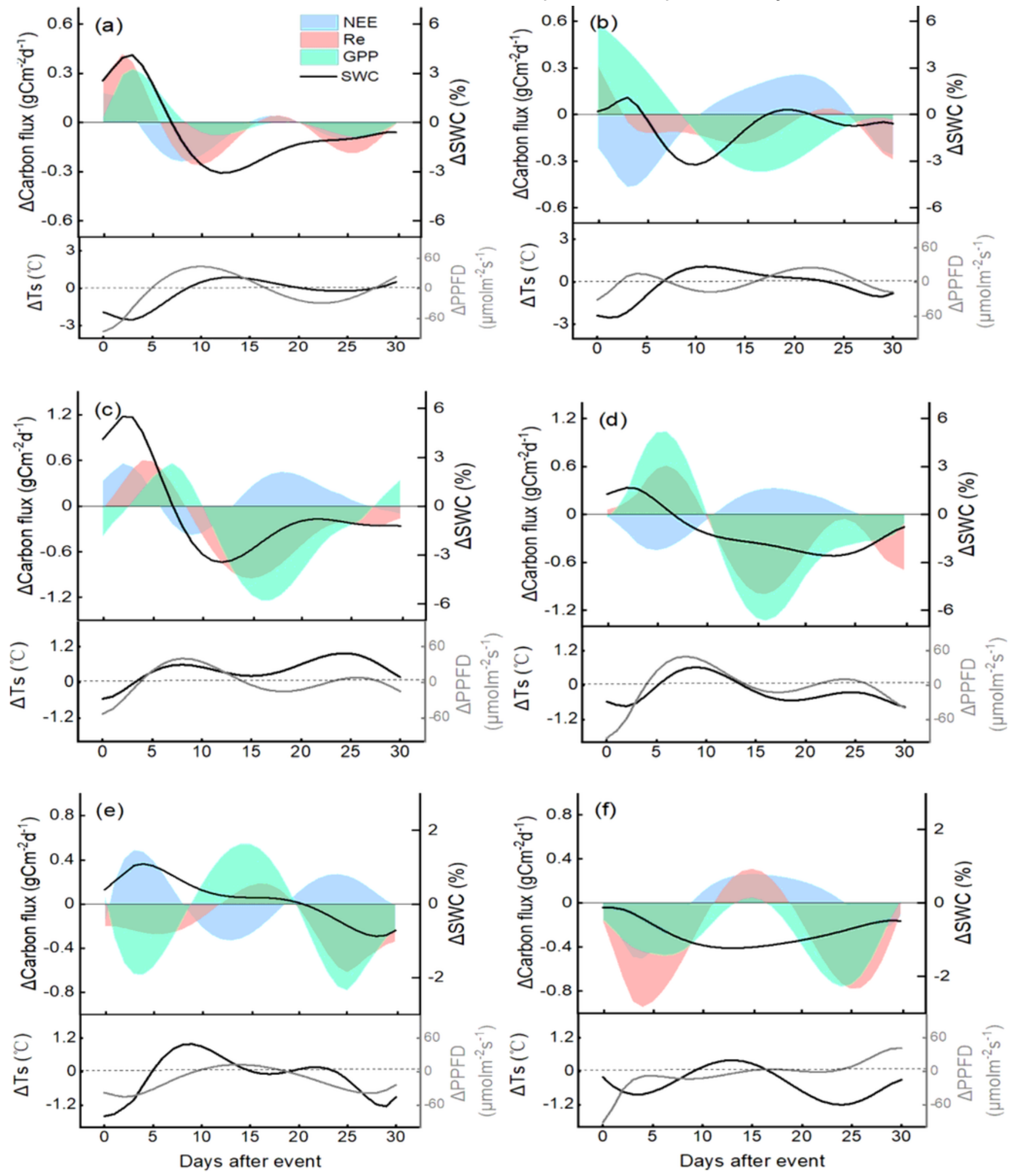

Figure 2 
Mean diurnal fluctuation of NEE, GPP, Re, SWC, Ts and PPFD following dry-EPEs for (a) arid, (c) semi-arid and (e) sub-humid sites, and wet-EPEs for (b) arid, (d) semi-arid and (f) sub-humid sites.

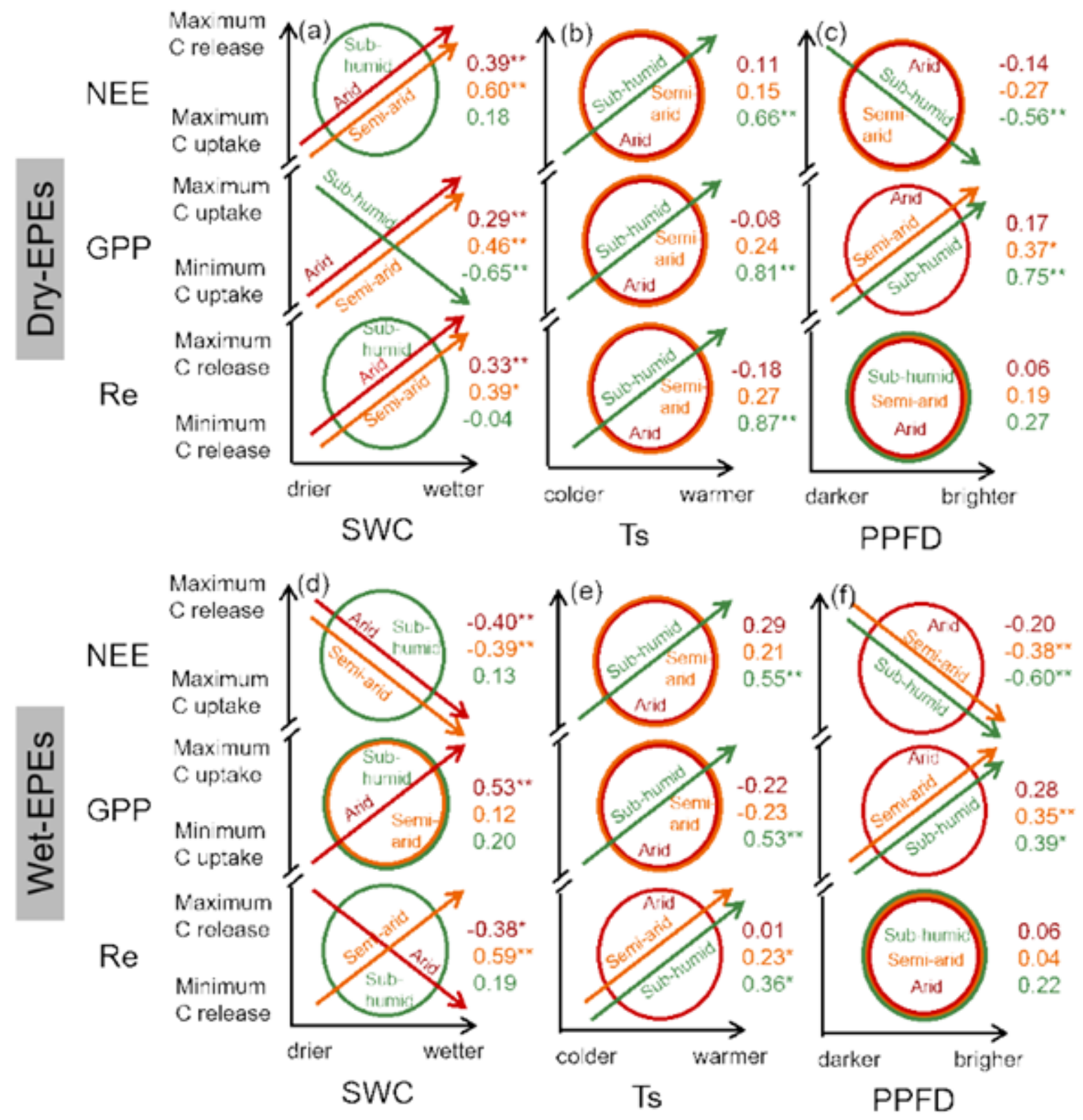

\section{Figure 3}

Schematic diagram of how diurnal NEE, GPP and Re within 15 days after EPEs to soil water content (SWC), soil temperature (Ts) and photosynthetic photon flux density (PPFD). (a), (b) and (c) illustrate variable responses after dry-EPEs. (d), (e) and (f) illustrate responses after wet-EPEs. Circles indicate no statistically significant relationship $(p>0.05)$ between carbon fluxes response and other factors. Ascending (descending) arrows indicate a statistically significant positive (negative) relationship ( $p<$ 0.05 ) between carbon fluxes responses and other variables. Red, orange and green arrow or circle in each subplot represent arid, semi-arid and sub-humid sites, respectively. The numbers on the right side of each subplot denote the partial correlation coefficients between carbon fluxes (NEE, GPP and Re) and 
environmental factors (SWC, Ts and PPFD) for arid (red), semi-arid (orange) and sub-humid (green) sites. * and $* *$ denote $p<0.05$ and $p<0.01$, respectively.
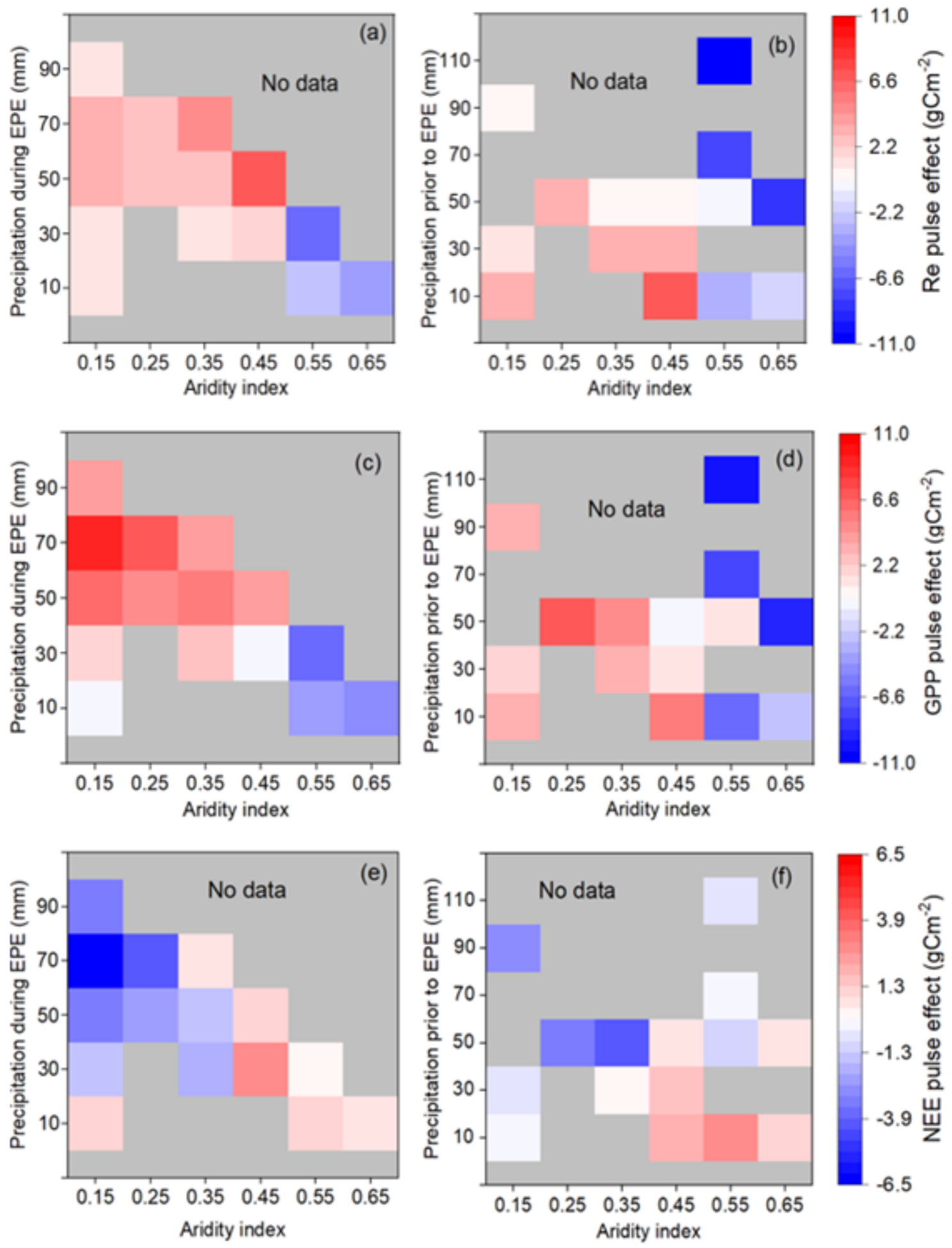

Figure 4

Accumulative pulsed Re $(a, b), \operatorname{GPP}(c, d)$ and $\operatorname{NEE}(e, f)$ following EPEs along the aridity gradient specified by the Aridity Index (Al), arid $(0.03 \leq \mathrm{Al}<0.2)$, semi-arid $(0.2 \leq \mathrm{Al}<0.5)$ and sub-humid $(0.5 \leq \mathrm{Al}$ 
$<0.65)$. Values shown in each box are means across all events characterized by respective EPEs intensity, antecedent precipitation and aridity index.

\section{Supplementary Files}

This is a list of supplementary files associated with this preprint. Click to download.

- Supplementary.docx 